\title{
JENIS TUMBUHAN DAN TIPE HABITAT DI HUTAN DATARAN RENDAH HAYA, MAMBERAMO, PAPUA
}

\section{The Plant Species and Type of Habitat in Lowland Forests of Haya, Mamberamo, Papua}

\author{
Marthen Jitmau ${ }^{1 *}$, Amon Rumbino ${ }^{2}$ \\ ${ }^{1}$ Pusat Penelitian Keanekaragaman Hayati, Universitas Papua, Manokwari 98314, Indonesia \\ ${ }^{2}$ Program Studi Biologi, Fakultas Matematika dan Ilmu Pengetahuan Alam Universitas Papua, Manokwari \\ 98314, Indonesia
}

*Korespondensi: Mjitmau @yahoo.com

\begin{abstract}
Mamberamo lowland areas are generally contains of primary rainforests. Until now, basic research needs to documentation all of biology resourches because of many other important genetic data, evolution, and their implication to conservation management are not realy know. On the other hand, the development of new regency (Daerah Otonom Baru or DOB) still available to certain habitat use. The purpose of this study is to analyse habitat diversity, and identify plant species scattered in lowland forests around the Haya village, Mamberamo. Total 123 species (40 of family) of plants were found in Haya. We found there are two families of plant with highly dominant spescies in this region i.e. Arecaceae with 12 species or $9.75 \%$, and 11 species of Moraceae (8.9\%) are dominant of famili of plant found in this region. There are tree type of habitat at Haya i.e. plains, hills and seasionally inundeted.
\end{abstract}

\begin{abstract}
ABSTRAK
Dataran rendah Mamberamo pada umumnya masih berupa hutan primer dan belum diteliti secara menyeluruh. Saat ini, masih diperlukan penelitian dasar untuk mendokumentasikan seluruh sumberdaya biologi karena banyak data penting genetik, evolusi dan implikasinya terhadap manajemen pelestarian belum diketahui secara pasti. Disisi lain, pemekaran wilayah DOB masih terus tersedia untuk menggunakan habitat tertentu. Tujuan penelitian ini adalah menganalisa keragaman habitat, dan mengidentifikasi spesies tumbuhan yang tersebar di hutan dataran rendah sekitar kampung Haya, Mamberamo. Total 123 spesies (40 famili) tumbuhan ditemukan di hutan dataran rendah Haya, Mamberamo. Famili dengan jumlah spesies terbanyak adalah Arecaceae 12 spesies $(9.75 \%)$ dan 11 spesies Moraceae (8.9\%). Terdapat tiga tipe habitat di Haya yaitu dataran rendah (plains), perbukitan rendah (hills), area yang secara musiman tergenang air (seasionally inundeted).
\end{abstract}

Keywords: Plant, Lowland, Habitat, Mamberamo

\section{PENDAHULUAN}

Habitat hutan tropik telah dan sedang mengalami fragmentasi dan pengurangan luasan di berbagai tempat akibat kegiatan antroposentris. Banyak hutan di Indonesia telah mengalami kerusakan parah seperti di Pulau Kalimantan dan Sumatera. Deforestasi di Papua

masih rendah tetapi kegiatan logging dan pembangunan pada masa mendatang sangat potensial bagi penigkatan kerusakan hutan. Disisi lain, upaya pelestarian hutan sebagai habitat berbagai jenis hewan terus diupayakan oleh berbagai pihak. 
Hutan-hutan Papua memiliki biodiversitas tumbuhan dan hewan yang spektakuler dan endemik, mewakili hampir setengah dari total biodiversitas negara Indonesia (Conservation International, 1999). Papua dengan kekayaan keanekaragaman hayati yang tinggi dengan sejumlah spesies endemik, sangat penting untuk dipertahankan secara alami.

Hutan sebagai habitat flora dan fauna memiliki nilai penting dalam menunjang komposisi keragaman, distribusi dan struktur komunitas yang ada. Semua tipe habitat perlu dipelihara sebagai satu ekosistem yang utuh, sehingga sepanjang waktu semua habitat tersebut mampu mendukung kelestarian populasi flora dan fauna secara alami. Secara umum hutanhutan dataran rendah di DAS Mamberamo saat ini masih baik.

Survey-survey flora dan fauna di daerah DAS Mamberamo telah dilakukan sejak lama, namun nelum pernah dilakukan di Haya, salah satu ekosistem hutan dataran rendah yang terkoneksi dengan system DAS Mamberamo. DAS Mamberamo sebagai sungai utama di utara Papua menampung seluruh aliran sungai kecil. Salah satu sungai kecil yang mengalir ke Sungai Mamberamo adalah Sungai Oii, dimana kampung Haya berada. Sungai Oii dengan aliran airnya yang cukup deras berlanjut hingga bergabung dengan salah satu cabang utama Sungai Mamberamo yakni Rouffaer. Aliran Sungai Mamberamo berbentuk seperti huruf " $T$ " terbalik, dengan dua cabang utama, Rouffaer di bagian barat dan Idenburg di bagian timur (Polhemus dan Richards, 2002).

Identifikasi dan dokumentasi flora serta kajian tipe-tipe habitat di Haya perlu dilakukan, sehingga data-data yang dihimpun dapat menjelaskan perubahan-perubahan habitat pada waktu mendatang. Tujuan penelitian ini adalah untuk medokumentasikan jenis-jenis tumbuhan dan menganalisa tipe-tipe habitat di area hutan dataran rendah Haya, Mamberamo, Papua.

\section{METODE}

\section{Koleksi Data Tumbuhan}

Penelitian ini dilakukan pada beberapa tipe habitat di hutan dataran rendah Haya. Metode yang digunakan adalah observasi lapang dengan teknik jelajah. Setiap tipe habitat dikunjungi untuk mendokumentasi jenis vegetasi dan membuat visualisasi fisik maupun biotik habitat.

Pengambilan data jenis tumbuhan dilakukan di area hutan (Tabel 1) di sepanjang sungai maupun kali, tepian rawa, telaga dan juga pada hutan sekunder dengan menelusuri jalur (jalan setapak) yang telah lama dibuat oleh masyarakat lokal. Data jenis tumbuhan yang diperoleh pada tiap lokasi pengamatan dicatat dan difoto, sedangkan tumbuhan yang belum teridentifikasi dibuat herbarium. Identifikasi selanjutnya dilakukan pada herbarium Manokwariense Universitas Papua di Manokwari.

\section{Analisa Data}

Data yang diperoleh selanjutnya dianalisa secara deskriptif. Fokus analisa pada jenis-jenis tumbuhan yang secara umum menguraikan karakteristik hutan dataran rendah dan kekayaan jenis tumbuhan di Haya.

\section{HASIL DAN PEMBAHASAN \\ Tipe Habitat}

Hutan Haya yang terletak pada altitud rendah 110-300 m dpl merupakan sebuah hamparan eksositem dataran rendah yang sangat luas (Gambar 1). Walaupun tidak dianalisa, namun jenis tanah di Haya sama dengan jenis tanah di daerah Kwerba yang dilaporkan oleh Conservation International yakni Entisol, Histosol, Inseptisol dan ultisol.

Terdapat tiga tipe habitat utama (domain habitat) yaitu hutan datar (plains), bukit rendah (hills) dan habitat perairan tawar yang sering mengalami pasang surut (seasonally inundated) yang meliputi rawa (swamp), telaga (oxbowlake) dan kali kecil (creeks). Tiga domain habaitat ini sangat menunjang kehidupan berbagai spesies fauna mulai dari serangga, ikan, katak, reptil, burung dan mamalia. Fauna-fauna ini selain disuport oleh ketersedian air yang cukup melimpah, juga oleh melimpahnya jenis pakan.

Secara umum hutan di Haya masih sangat baik. Jenis vegetasi dari famili Moraceae mendominasi famili lainnya pada tipe habitat seasonally inundated, sedangkan pada tipe habitat hills didominasi oleh famili Arecaceae. 


\begin{tabular}{|c|c|c|}
\hline $\begin{array}{l}\text { Lokasi } \\
\text { Survey }\end{array}$ & $\begin{array}{l}\text { Deskripsi Lokasi Survey dengan sejumlah data fisik perairan } \\
\text { dan kondisi curah hujan selama penelitian }\end{array}$ & $\begin{array}{l}\text { Koordinat } \\
\text { GPS/Altitud }\end{array}$ \\
\hline $\begin{array}{l}\text { Sungai } \\
\text { Oii }\end{array}$ & $\begin{array}{l}\text { Terletak di bagian utara Kampung Haya. Oii merupakan sungai } \\
\text { terbesar di Haya dengan arus yang deras, dan air keruh sepanjang } \\
\text { tahun. Vegetasi riparia memiliki tutupan kanopi yang cukup } \\
\text { lebat. Saat hujan lebat air sungai meluap dan menggenangi } \\
\text { daerah sekitarnya. Substrat dasar perairan berpasir, berlumpur } \\
\text { dan sedikit berbatu hingga kedalaman } \pm 2-4 \mathrm{~m} \text {. }\end{array}$ & $\begin{array}{l}\text { S:0249’29"' } \\
\text { E: } 138^{\circ} 06^{\prime} 032^{\prime \prime} \\
\text { Altitud: } 90 \mathrm{~m} \mathrm{dpl}\end{array}$ \\
\hline $\begin{array}{l}\text { Kali } \\
\text { Kuahuwei }\end{array}$ & $\begin{array}{l}\text { Terletak di bagian barat Kampung Haya di daerah hutan dataran } \\
\text { (plains) dan terus mengalir sampai di sebelah timur Haya. Saat } \\
\text { hujan air kali akan melimpah dan menggenangi daerah sekitar, } \\
\text { jika musim panas air kali akan surut sehingga membentuk } \\
\text { seperti parit-parit yang tergenang. Vegetasi disepanjang kali } \\
\text { berupa tutupan kanopi hutan yang lebat. Arus air relatif deras } \\
\text { sampai tenang dengan air jernih dan keruh saat musim hujan. } \\
\text { Substrat dasar perairan berlumpur, serasah, dan pasir dengan } \\
\text { kedalaman } \pm 0,5-2 \mathrm{~m} \text {. }\end{array}$ & $\begin{array}{l}\text { S:02 } 48^{\prime} 718^{\prime \prime} \\
\text { E:138 } 06^{\prime} 611^{\prime \prime} \\
\text { Altitud: } 90 \mathrm{~m} \mathrm{dpl}\end{array}$ \\
\hline $\begin{array}{l}\text { Kali } \\
\text { Koruwe }\end{array}$ & $\begin{array}{l}\text { Terletak di bagian timur Kampung Haya di daerah hutan dataran } \\
\text { (plains) dan menyatu ke Kali Kuahuwei. Kali ini sedikit lebih } \\
\text { kecil dari Kali Kuahuwei dengan tutupan hutan riparia yang } \\
\text { lebat. Arus air relatif tenang dengan warna air jernih, pada saat } \\
\text { hujan warna air keruh dan menggenangi daerah sekitar. Substrat } \\
\text { dasar perairan berlumpur, serasah, dan berpasir dengan } \\
\text { kedalaman } 0,5-1 \mathrm{~m} \text {. }\end{array}$ & Altitud: 90 m dpl \\
\hline Telaga & Terletak di rawa-rawa (swamps) bagian utara Kampung Haya $( \pm$ & $\mathrm{S}: 02^{\circ} 49^{\prime} 216^{\prime \prime}$ \\
\hline Kerjakeri/ & $100 \mathrm{~m}$ dari kampung). Telaga ini terbentuk dari aliran Sungai Oii & E:13806’402” \\
\hline Kedaket & $\begin{array}{l}\text { yang terputus, terlihat dari bentuk telaga yang memanjang. } \\
\text { Permukaan air banyak ditutupi tumbuhan air sedangkan vegetasi } \\
\text { pinggir telaga berupa pohon sagu dan tumbuhan air lainnya. } \\
\text { Warna air kelihatan hitam pekat dengan substrat dasar perairan } \\
\text { berlumpur. Luas telaga kurang lebih } 4-5 \text { hektar dengan kedalam } \\
\text { kurang lebih } 1-3 \text { m. }\end{array}$ & Altitud: 90 m dpl \\
\hline Telaga & Terletak di rawa-rawa (swamps) bagian timur Kampung Haya & $\mathrm{S}: 02^{\circ} 48^{\prime} 947^{\prime}$ \\
\hline Suuda/ & ( $\pm 1 \mathrm{~km}$ dari kampung). Telaga ini juga terbentuk dari aliran & E: $138^{\circ} 06^{\prime} 625^{\prime \prime}$ \\
\hline Suurja & $\begin{array}{l}\text { Sungai Oii yang terputus dengan bentuk memanjang. Permukaan } \\
\text { air tidak ditutupi tumbuhan air sedangkan vegetasi disekitar } \\
\text { telaga berupa semak belukar. Warna air relatif jernih dengan } \\
\text { substrat dasar perairan berlumpur. Luas telaga kurang lebih } 2-3 \\
\text { hektar dengan kedalaman } 1-2 \mathrm{~m} \text {. }\end{array}$ & Altitud: $100 \mathrm{~m} \mathrm{dpl}$ \\
\hline $\begin{array}{l}\text { Sungai } \\
\text { Kra }\end{array}$ & $\begin{array}{l}\text { Terletak di hutan perbukitan (hills) bagian timur Kampung Haya } \\
( \pm 10 \mathrm{~km} \text { dari kampung). Sungai Kra mewakili sistem sungai } \\
\text { perbukitan (stream) berbatu dengan aliran air yang kurang deras } \\
\text { dan jernih. Kedalaman sungai bervariasi dari yang dangkal } \\
\text { beberapa cm saja sampai kedalaman } 2 \mathrm{~m} \text {, terutama pada bagian } \\
\text { lubuk/jeram (pool zone) dengan substrat berbatu dan berpasir. } \\
\text { Hutan primer dengan vegetasi riparia sangat rapat. }\end{array}$ & $\begin{array}{l}\text { S:0244'544" } \\
\text { E: } 138^{\circ} 05^{\prime} 903 " \\
\text { Altitud: } 200 \mathrm{~m} \mathrm{dpl}\end{array}$ \\
\hline
\end{tabular}

Selama penelitian berlangsung, teramati bahwa pembukaan-pembukaan areal hutan oleh masyarakat lokal hanya diperuntukkan bagi lahan pertanian skala kecil sebagai pemenuhan kebutuhan makan keluarga. Aktifitas perburuan sering dilakukan oleh masyarakat lokal secara tradisional. Hewan-hewan buruan biasanya adalah babi, kanguru, kuskus dan beberapa jenis burung. Mata pencaharian masyarakat Haya umumnya adalah petani dan peramu sagu. 
Hutan Haya merupakan sumberdaya yang sangat penting bagi penduduk setempat. Dengan populasi penduduk yang rendah telah membuka hutan menjadi lahan kebun tapi dalam skala sangat kecil. Masyarakat Haya yang terdiri dari tiga suku besar (Outai, Soutai dan Kausa) sangat mendukung adanya kegiatan konservasi di daerah mereka, sehingga perlu adanya tindakan-tindakan perlindungan hutan jangka panjang.

Pemanfaatan sumberdaya hutan (tumbuhan dan hewan) oleh masyarakat Haya masih tergolong ramah lingkungan dan berkelanjutan. Banyak fauna dapat dengan mudah ditemukan di dekat kampung karena hutan alami yang luas dan tidak terganggu berdampingan langsung dengan pemukiman.

\section{Dokumentasi Jenis Tumbuhan}

Sebanyak 123 jenis tumbuhan dari 40 famili berhasil diidentifikasi dalam survey ini. Klasifikasi 40 famili dilakukan berdasarkan ciri- ciri umum dan khusus dari taksa yang diobservasi dan disesuaikan dengan kunci identifikasi. Famili Arecaceae (12 jenis atau 9.75\%) dan Moraceae (11 jenis atau $8.9 \%$ ) mendominasi seluruh famili tumbuhan yang ada di Haya (Gambar 2). Berdasarkan analisa lanjutan tercatat familifamili yang ditemukan hanya memiliki satu jenis sebanyak $14(35 \%)$ famili.

Data jumlah jenis tumbuhan yang ditemukan dalam penelitian ini merupakan akumulasi jumlah jenis dari semua tipe habitat yang teridentifikasi (Gambar 3). Jika dibandingkan dengan hasil survey lainnya di dataran rendah Mamberamo, Dabra, ditemukan 121 jenis dalam plot ukuran 0,5 ha ( De Fretes et al., 2002). Sangat tidak mungkin untuk dilakukan perbandingan jenis vegetasi antara kedua lokasi Haya dan Dabra karena metode dan teknik sampling yang digunakan pada kedua lokasi berbeda. Walaupun demikian, data jenis yang ada cukup mewakili komposisi vegetasi di Haya.

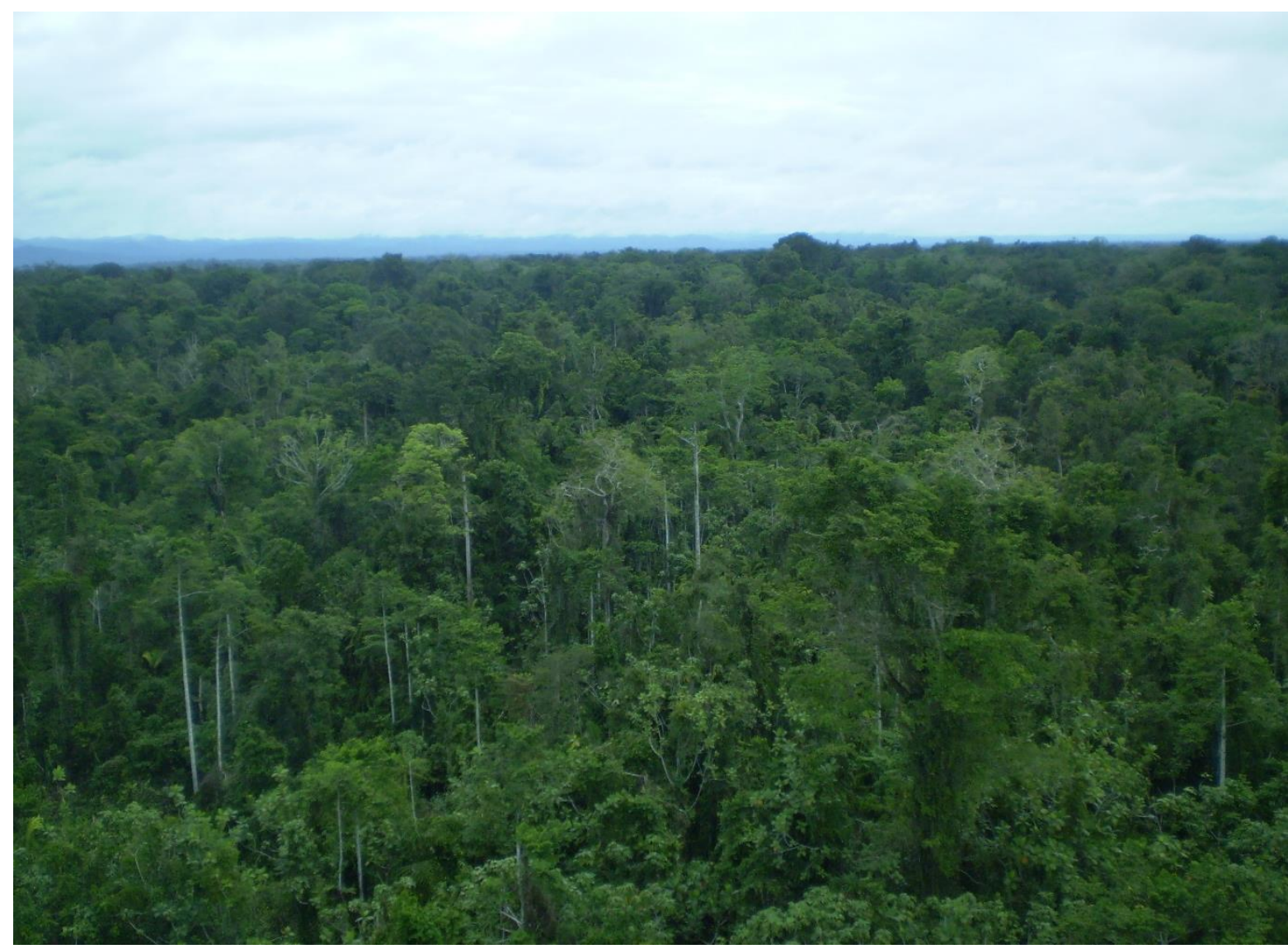

Gambar 1. Landskap hutan dataran rendah Haya, Mamberamo, Papua 


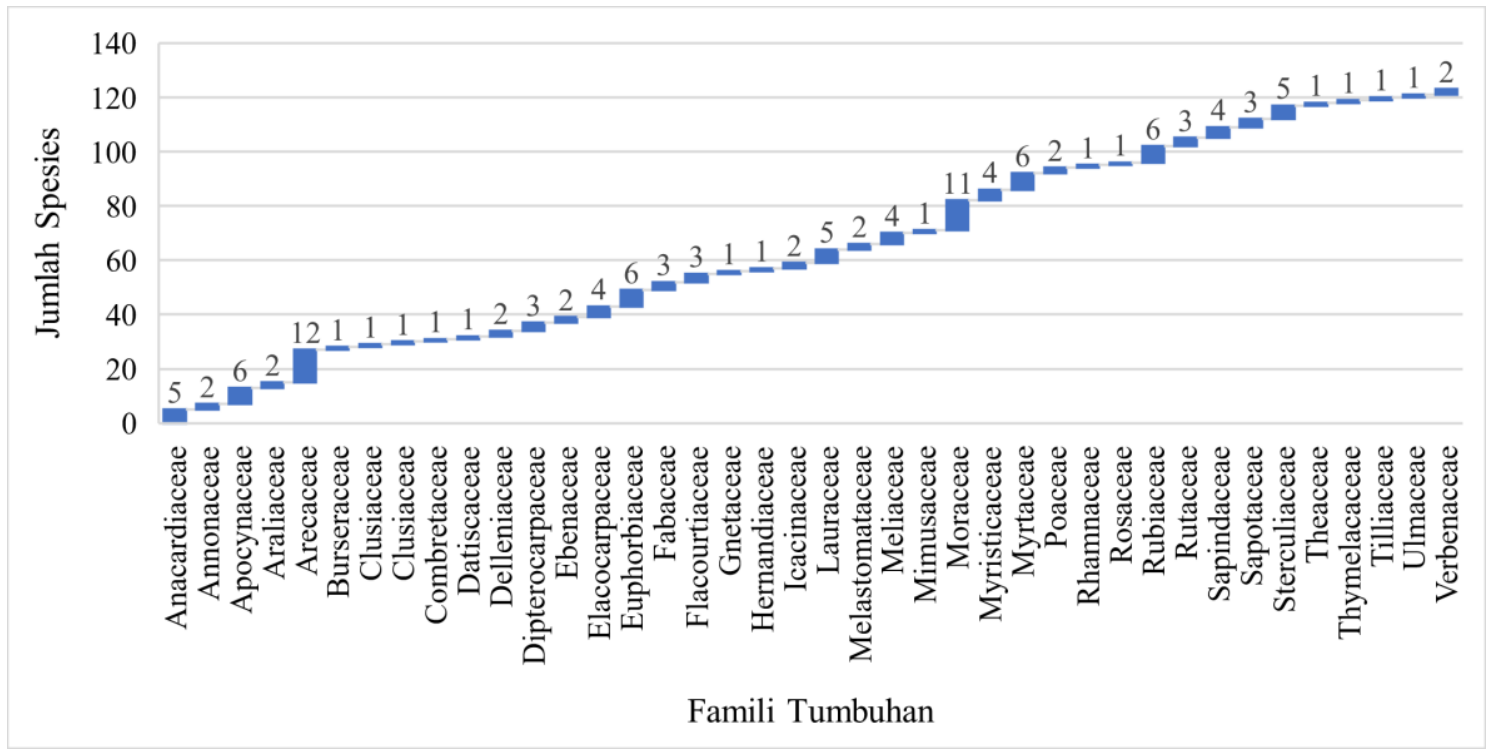

Gambar 2. Akumulasi jumlah spesies per famili tumbuhan dari hutan daratan rendah Haya

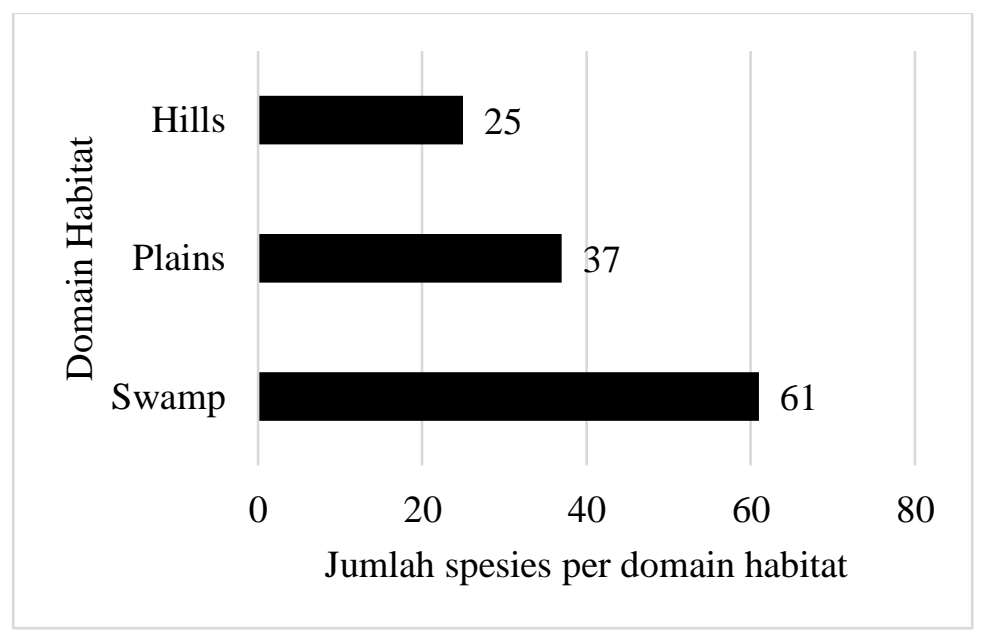

Gambar 3. Jumlah spesies tumbuhan per domain habitat di Haya

Sebagian besar area hutan milik masyarakat Haya secara adat adalah lahan konsesi perusahaan kayu PT. Mamberamo Alasmandiri. Dalam Rencana Kerja Tahunan (RKT) perusahan kayu ini menunjukkan bahwa area ini akan ditebang pada tahun 2030-an. Disisi lain, wilayah hutan sekitar Haya masuk kriteria sebagai Key Biodiversity Area dan juga hutan dengan nilai konservasi tinggi (High Conservation Value Forest - HCV) karena hutan ini mendukung populasi jenis-jenis flora maupun fauna yang terancam punah.

\section{SIMPULAN}

Sebanyak 123 spesies tumbuhan mewakili 40 famili tersebar pada tiga domain hutan datar (plains), bukit rendah (hills) dan habitat perairan tawar yang sering mengalami pasang surut (seasonally inundated) yang meliputi rawa (swamp), telaga (oxbowlake) dan kali kecil (creeks).

\section{UCAPAN TERIMA KASIH}

Penelitian ini merupakan hasil kerjasama Conservation International dengan Jurusan Biologi FMIPA UNIPA. Terkait itu, ucapan trima kasih kami sampaikan kepada kedua institusi ini. Terima kasih khusus kepada Mr. Neville Kemp dan Keliopas Krey yang telah memimpin tim peneliti selama di lapangan dan membantu dalam proses editing dan kontribusi beberapa foto. 


\section{DAFTAR PUSTAKA}

Conservation International. 1999. The Irian Jaya

Biodiversity Conservation Priority-Setting

Workshop: Final report. Washington, DC:

Conservation International.

De Fretes Y. Rachman IA dan Wally E. 2002. Vegetation of the Dabra area, Mamberamo River Basin, Papua, Indonesia. Dalam: Richards SJ, Suryadi S, editor. 2002. A Biodivrsity Assessment of Yongsu-Cyclops Mountains and the Southern Mamberamo Basin, Papua, Indonesia. RAP Bulletin of Biological Assessment 25. Washington DC: Conservation International.
Polhemus DA., Richards S. 2002. Geographic overview of the Cyclops Mountains and the Mamberamo Basin. Dalam: Richards SJ, Suryadi S, editor. 2002. A Biodivrsity Assessment of Yongsu-Cyclops Mountains and the Southern Mamberamo Basin, Papua, Indonesia. RAP Bulletin of Biological Assessment 25. Washington DC: Conservation International. 